\title{
Effect of Wire Tension on Rate of Weight Bearing in Ilizarov Apparatus
}

\author{
Mohammad Reza Effatparvar ${ }^{1 *}$ and Alireza Asghari Ardabili ${ }^{2}$ \\ ${ }^{1}$ Department of Biomedical Engineering, University of Isfahan, Iran \\ ${ }^{2}$ Department of Manufacturing Engineering, University of Tabriz, Iran
}

*Corresponding author: Mohammad Reza Effatparvar, MSc of Biomedical Engineering, Department of Biomedical Engineering, Faculty of Engineering, University of Isfahan, Kargar st, Tehran, Iran.

To Cite This Article: Mohammad Reza Effatparvar and Alireza Asghari Ardabili. Effect of Wire Tension on Rate of Weight Bearing in Ilizarov Apparatus. Am J Biomed Sci \& Res. 2019 - 3(4). AJBSR.MS.ID.000686. DOI: 10.34297/AJBSR.2019.03.000686

Received: June 10, 2019 | Published: June 20, 2019

\begin{abstract}
K-wires play an important role in stability of Ilizarov fixator. In this fixation system, wires are tensioned for bearing patient weight. In this study, measuring of vertical bending of k-wire would show the effect of horizontal tension of wire. Russian Ilizarov K-wires were inserted into artificial tibia sawbones and fixed on the ring. Then, after wire tensions in range of $70 \mathrm{~kg}$ to $130 \mathrm{~kg}$ by tensioner device and vertical forces of $40 \mathrm{~kg}$ to $100 \mathrm{~kg}$ by bending test device, vertical displacements were measured. 49 data about to wire displacements are recorded. in the minimum horizontal tension (P) $(70 \mathrm{~kg})$ and maximum vertical loading (F) $(100 \mathrm{~kg})$, the rate of vertical displacement $(\mathrm{Y})$ received to the highest amount $(0.837 \mathrm{~cm})$, but in condition that $\mathrm{P}$ was maximum $(130 \mathrm{~kg})$ and $\mathrm{F}$ was minimum $(40 \mathrm{~kg})$ the amount of $\mathrm{Y}$ got to the lowest point $(0.112)$. Regarding to the obtain data, effect of k-wire tensile on decreasing the vertical displacement and prevent from k-wire cutting is obviously Figure out. More tension is better way to earning stability. This should be noted; the maximum amount of tension is the half of yield point.
\end{abstract}

Keywords: K-Wire; Ilizarov; Tension; Vertical Displacement

\section{Introduction}

Krishner wire or k-wire is a pin which used in orthopedic surgeries. One of the main applications of these wires is in Ilizarov external fixation. In this method wire is inserted into bone from one side and extracted from other side [1]. The wire must be fixed on the ring of Ilizarov frame from one end by wire fixation bolt and tensioned from another end by tensioner device [2]. The fixation strength has a direct relation to the tension of the wires $[3,4]$. This performance is like to the bicycle spokes tension for increasing weight bearing. Not enough wire tension will lead to multiple bending and finally wire cutting [5]. Basically, the tension rate of the wires depends on patient weight [6,7]. Standard range of tension for stainless steel wire with diameter of $1.8 \mathrm{~mm}$ is $70 \mathrm{~kg}$ to $130 \mathrm{~kg}$ [5]. In this experiment effect of tension on vertical displacement of wire will investigated.

\section{Material and Method}

An artificial tibia sawbones with diameter of $40 \mathrm{~mm}$ was used as a bone simulator. Stainless steel k-wires of Russian Ilizarov scientific center with diameter of $1.8 \mathrm{~mm}$ were inserted into sawbones by drill. Then wire fixed and locked from one side by wire fixation bolt on the stainless-steel ring of Indian Pitkar Company with diameter of $160 \mathrm{~mm}$. In next step, wire was tensioned by Russian Ilizarov scientific center tensioner device from $70 \mathrm{~kg}$ to $130 \mathrm{~kg}$ with $10 \mathrm{~kg}$ intervals. After applying each step of the tension, this set from the center was located at the site of the Gotech AI-7000M bending test device. The vertical force on wire, which simulates the force of the body weight was inserted from $40 \mathrm{~kg}$ to $100 \mathrm{~kg}$ with $10 \mathrm{kh}$ intervals. The process of test is showed below. In process, wire is tensioned by amount of $\mathrm{P}$ then vertical force of $\mathrm{F}$ is applied and displacement $(\mathrm{y})$ is recorded (Figure 1).

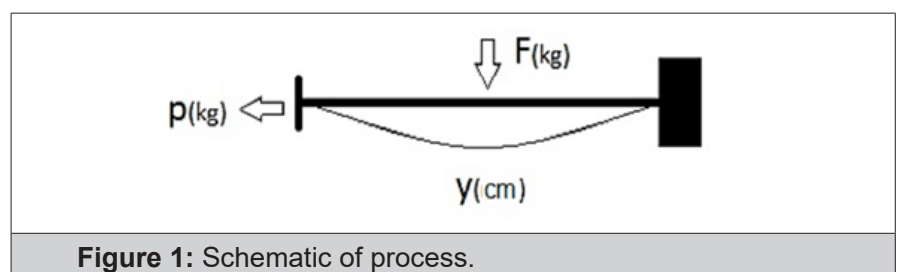

\section{Results and Discussion}

After conducting several experiments, k-wire vertical displacements (y) were recorded as shown in Table 1. In the table 
above, the values of $\mathrm{F}$ mean the tensions entered the wires in kilograms and the values of $\mathrm{P}$ are the weights entered vertically on the wires in kilograms. Each cell inside the table show the amount of displacements or the pin's bending, in $\mathrm{cm}$. For example, the bending of the wire in the case of $130 \mathrm{~kg}$ tension (F) and $100 \mathrm{~kg}$ vertical force $(p)$ is $0.396 \mathrm{~cm}$. The highest vertical displacement of $837.0 \mathrm{~cm}$ is related to horizontal stretching of $70 \mathrm{~kg}$ and vertical loading of $100 \mathrm{~kg}$.

\begin{tabular}{|c|c|c|c|c|c|c|c|}
\hline \multicolumn{1}{|l|}{ Table 1: Experimental results. } \\
\hline $\mathbf{F}$ & $\mathbf{P = 4 0 k g}$ & $\mathbf{P = 5 0 k g}$ & $\mathbf{P = 6 0 k g}$ & $\mathbf{P = 7 0 k g}$ & $\mathbf{P = 8 0 k g}$ & $\mathbf{P = 9 0 k g}$ & $\mathbf{P}=\mathbf{1 0 0 k g}$ \\
\hline $\mathrm{F}=70 \mathrm{~kg}$ & 0.409 & 0.468 & 0.543 & 0.602 & 0.679 & 0.759 & 0.837 \\
\hline $\mathrm{F}=80 \mathrm{~kg}$ & 0.344 & 0.412 & 0.462 & 0.541 & 0.61 & 0.671 & 0.764 \\
\hline $\mathrm{F}=90 \mathrm{~kg}$ & 0.296 & 0.339 & 0.418 & 0.473 & 0.55 & 0.614 & 0.674 \\
\hline $\mathrm{F}=100 \mathrm{~kg}$ & 0.253 & 0.302 & 0.347 & 0.41 & 0.459 & 0.549 & 0.601 \\
\hline $\mathrm{F}=110 \mathrm{~kg}$ & 0.201 & 0.248 & 0.287 & 0.35 & 0.404 & 0.473 & 0.538 \\
\hline $\mathrm{F}=120 \mathrm{~kg}$ & 0.162 & 0.196 & 0.259 & 0.296 & 0.351 & 0.4 & 0.46 \\
\hline $\mathrm{F}=130 \mathrm{~kg}$ & 0.112 & 0.153 & 0.209 & 0.249 & 0.289 & 0.348 & 0.396 \\
\hline
\end{tabular}

The axial tensile force on the k-wire in Ilizarov external fixator is the most basic method of stability. The experiments in this paper have clear results regarding the need for horizontal tension in the wire to increase the apparatus weight bearing capacity. It should be noted that, more $\mathrm{k}$-wires usage in one ring will lead to more stability and lesser displacement. As can be seen from the table's results, in each raw, from left to right, and in each column from down to up the numbers are incremental. In this test, while the axial tensile force increases from 70 to $130 \mathrm{~kg}$ the rate of bending or vertical displacement $(\mathrm{Y})$ decreases. But it should not be forgotten that the hypertension of $\mathrm{k}$-wire because of diameter change will result inversely. When the tension of k-wire (p) be close to the loading amount (F), vertical displacement will be less. But if the bearing of wire gets more than tension rate, the amount of vertical displacement will increase linearly [8]. Most of the time, k-wire cutting is Due to increased fatigue rates because of multiple bends.

\section{Conclusion}

Finally, the results show, the maximum displacement is occurred in minimum tension and maximum bearing, In the case of a k-wire usage for a person with a high weight, tensile force should be increased in proportion to the weight of the patient.

\section{References}

1. Board T, L Yang, M Saleh (2007) Why fine-wire fixators work: an analysis of pressure distribution at the wire-bone interface. J Biomech 40(1): 2025.
2. Gessmann J, Jettkant B, Königshausen M, Schildhauer TA, Seybold D (2012) Improved wire stiffness with modified connection bolts in Ilizarov external frames: a biomechanical study. Acta Bioeng Biomech 14(4): 15-21.

3. Watson MA, K J Matthias, N Maffulli, D W L Hukins (2003) Yielding of the clamped-wire system in the Ilizarov external fixator. Proceedings of the Institution of Mechanical Engineers, Part H: Journal of Engineering in Medicine 217(5): 367-374.

4. Wosar MA, DJ Marcellin-Little, SC Roe (2002) Influence of bolt tightening torque, wire size, and component reuse on wire fixation in circular external fixation. Vet Surg 31(6): 571-576.

5. Solomin L (2013) The basic principles of external skeletal fixation using the Ilizarov and other devices. Springer Science \& Business Media.

6. Roberts CS, Antoci V, Antoci V, Voor MJ (2004) The accuracy of fine wire tensioners: a comparison of five tensioners used in hybrid and ring external fixation. J Orthop Trauma 18(3): 158-162.

7. Stein H, Perren SM, Mosheiff R, Baumgart F, Cordey J (2001) Decline in transfixing K-wire tension of the circular external fixator: experimental continuous in vivo measurements. Orthopedics 24(10): 985-989.

8. La Russa V, Olav A Foss, Jomar Klaksvik, Bjørn Skallerud (2010) Wire tension versus wire frequency: an experimental Ilizarov frame study. Journal of Biomechanics 43(12): 2327-2331. 